
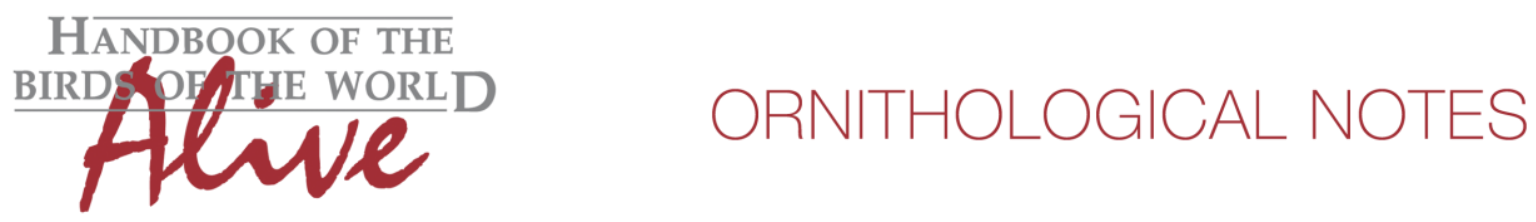

\title{
Notes on the vocalizations of Black-cowled Saltator (Saltator nigriceps)
}

Peter Boesman

In the following we briefly analyze and compare voice of Black-cowled Saltator (Saltator nigriceps) with the different races of Golden-billed Saltator (Saltator aurantiirostris). We also try to quantify the extent of any vocal differences using the criteria proposed by Tobias et al. (2010), as a support for taxonomic review. We have made use of sound recordings available on-line from Xeno Canto (XC).

Song of S. nigriceps is quite variable, but always starts with a short intro note followed by a loud squeeky (polyphonic) whistle. The whistle is usually quite complex, typically sharply going up and down in pitch (but sometimes reversely going down and up, or much simpler in shape, then sometimes rather like a call note). When looked at in more detail on a sonogram, the whistle seems to be always the superposition of two notes (not harmonics, hence polyphonic), suggesting both sides of the syrinx are independent oscillators and utter each a very different note. Some examples, illustrated with sonograms:

Ecuador
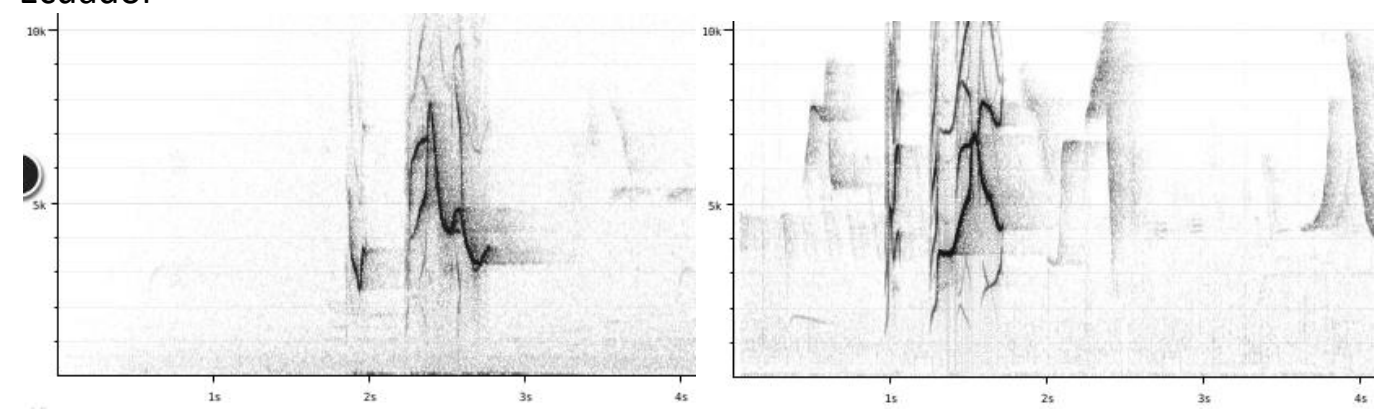

Peru
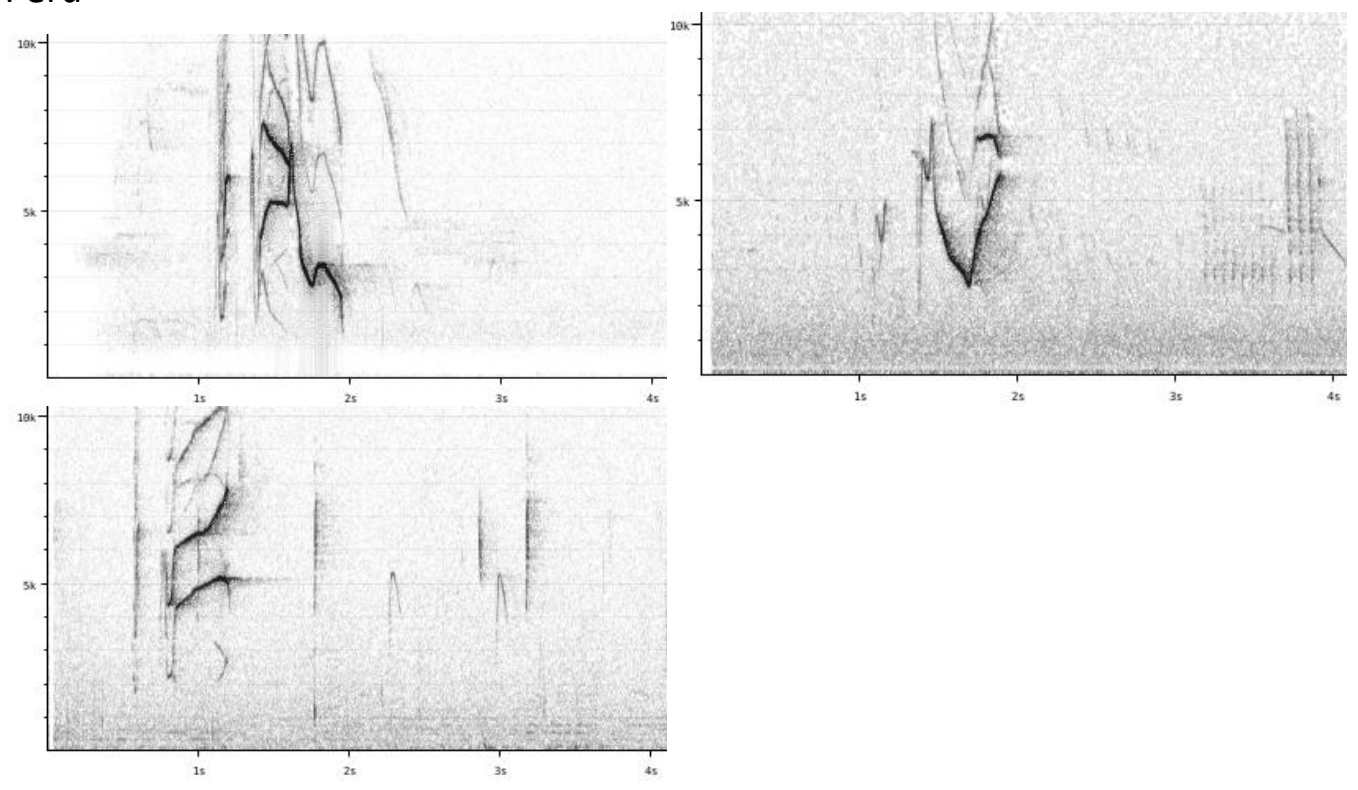


\section{HANDBOOK OF THE Alve}

\section{ORNITHOLOGICAL NOTES}

Call is a high-pitched short "tsee" (Other apparent call notes may well be simple versions of song; all other XC recordings denominated "call" were actually clearly song phrases: intro + two simultaneous whistles)

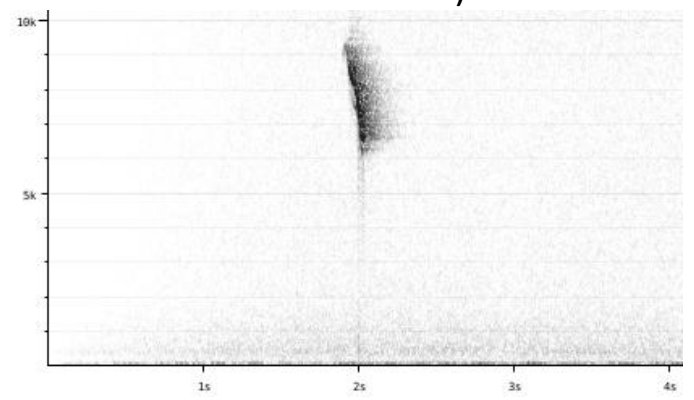

Song of S. aurantiirostris is quite variable, a short phrase of several notes, with at least a few notes steeply upslurred or downslurred. In all races, song varies from a simple phrase consisting of a few short notes followed by a loud pure whistle (often upslurred), to more complex phrases with more loud notes. All notes are monophonic.

Some examples:

S. a. iteratus (N Peru)
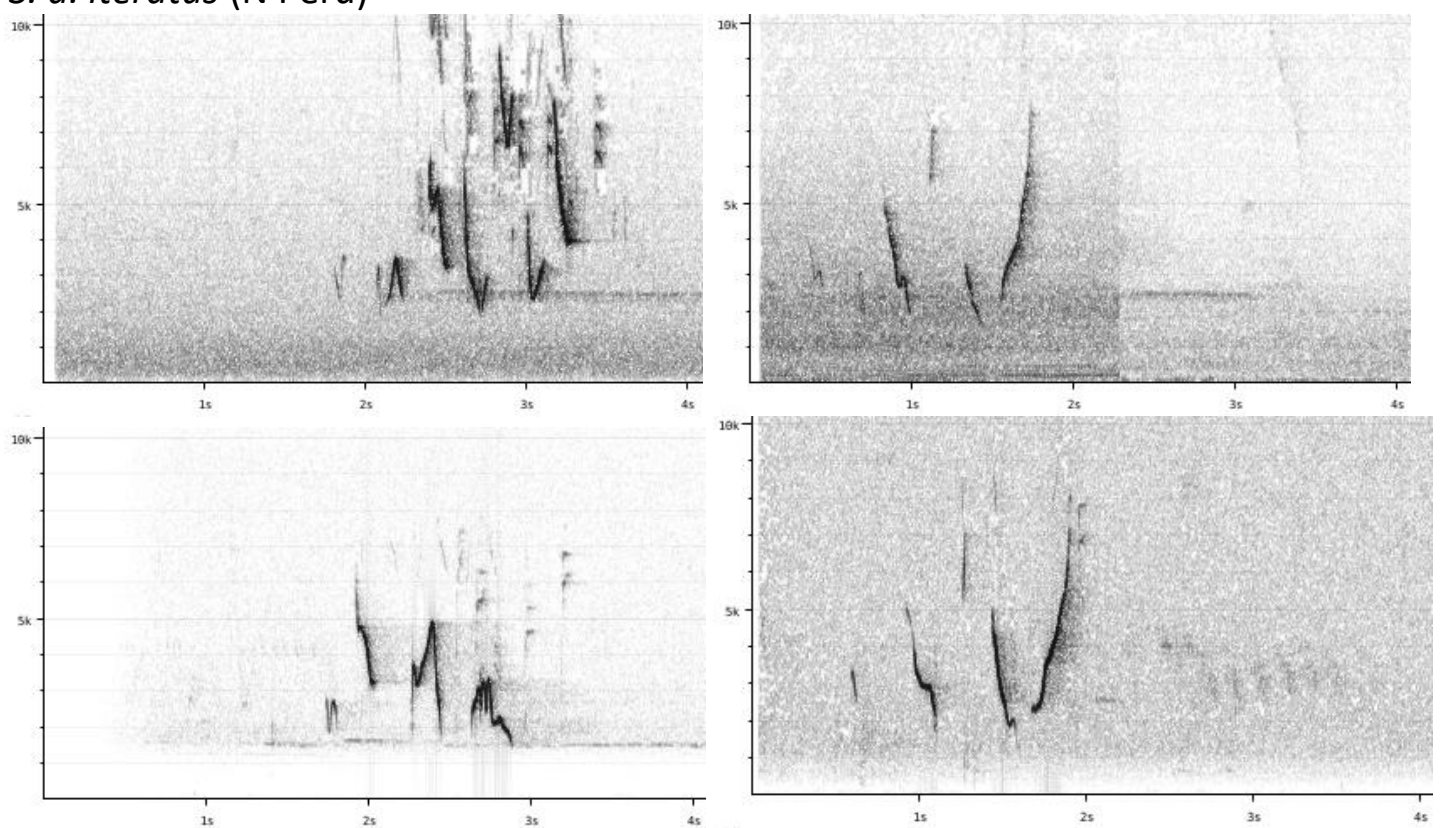

S. a. albociliaris (C \& S Peru and extreme N Chile)
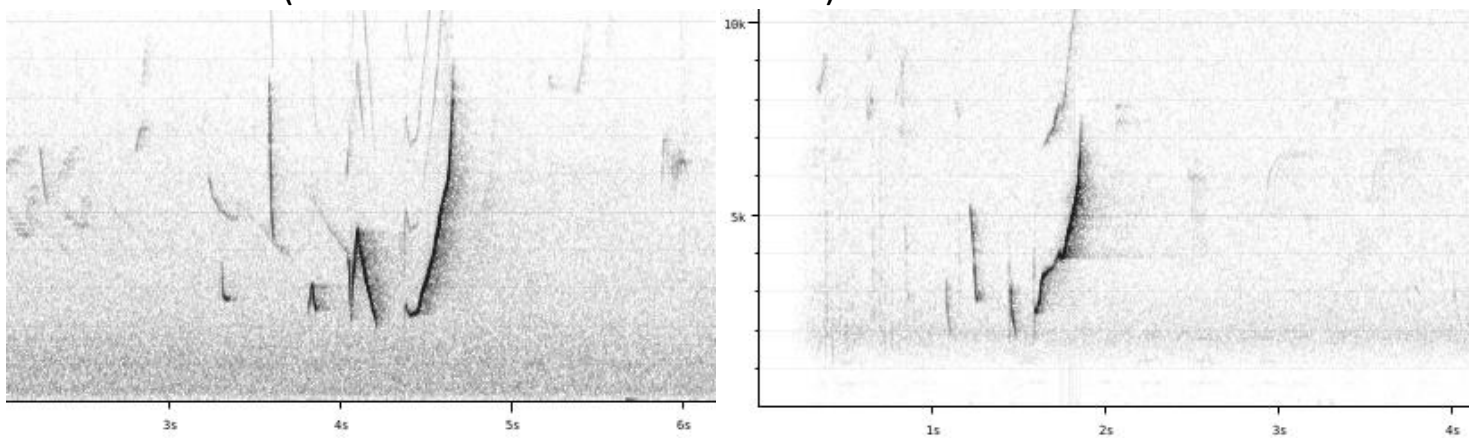
HANDBOOK OF THE

BIRDS PF/THE WORLD

Alive

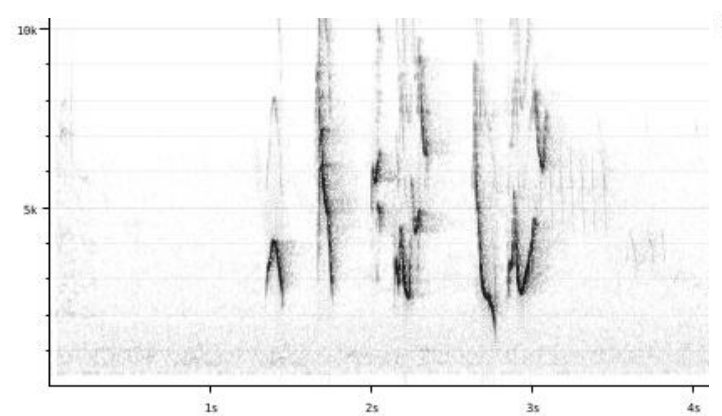

S. a. hellmayri (Bolivia)
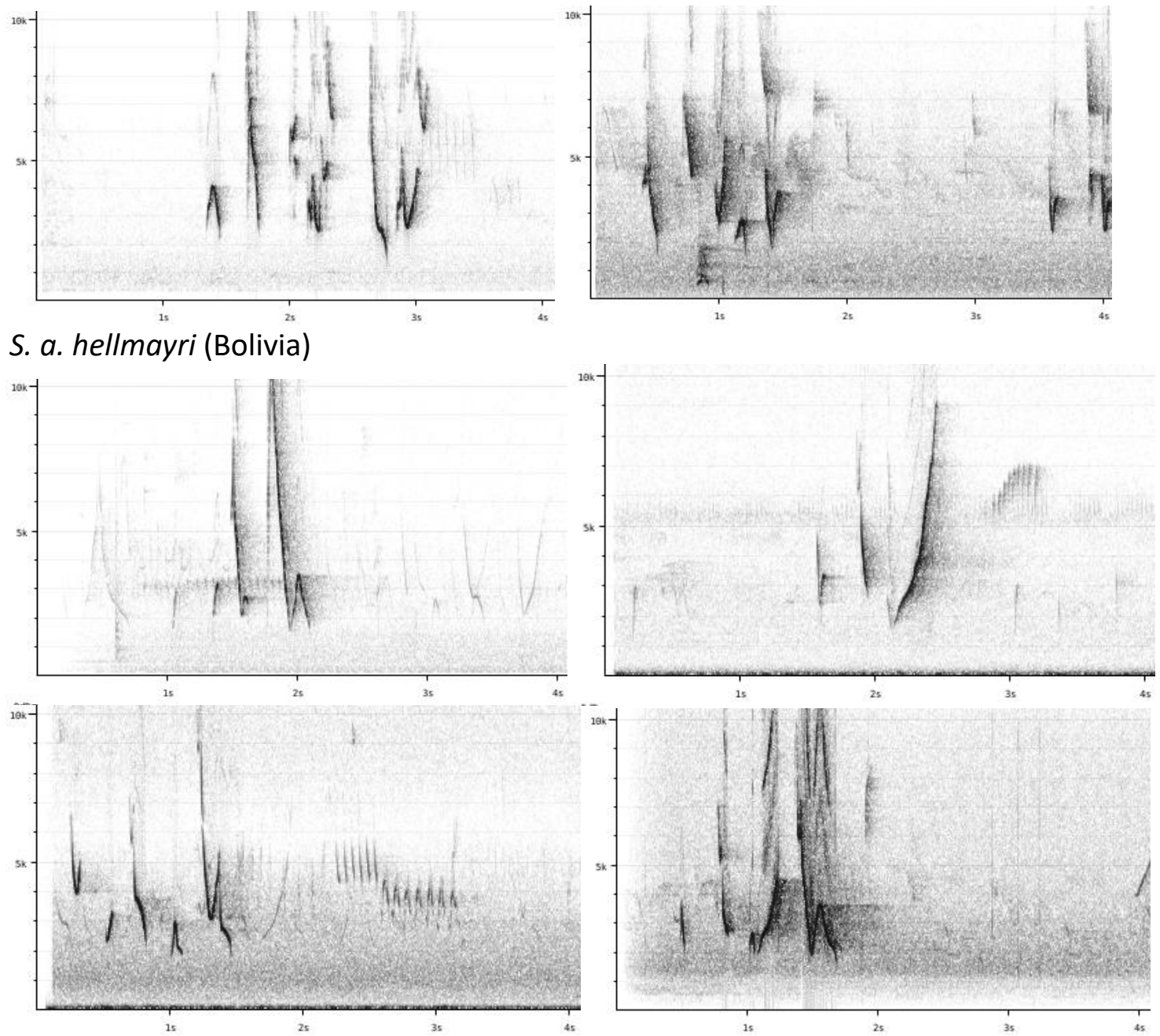

S. a. aurantiirostris (Bolivia (S Tarija), N Argentina, E Paraguay and S Brazil)
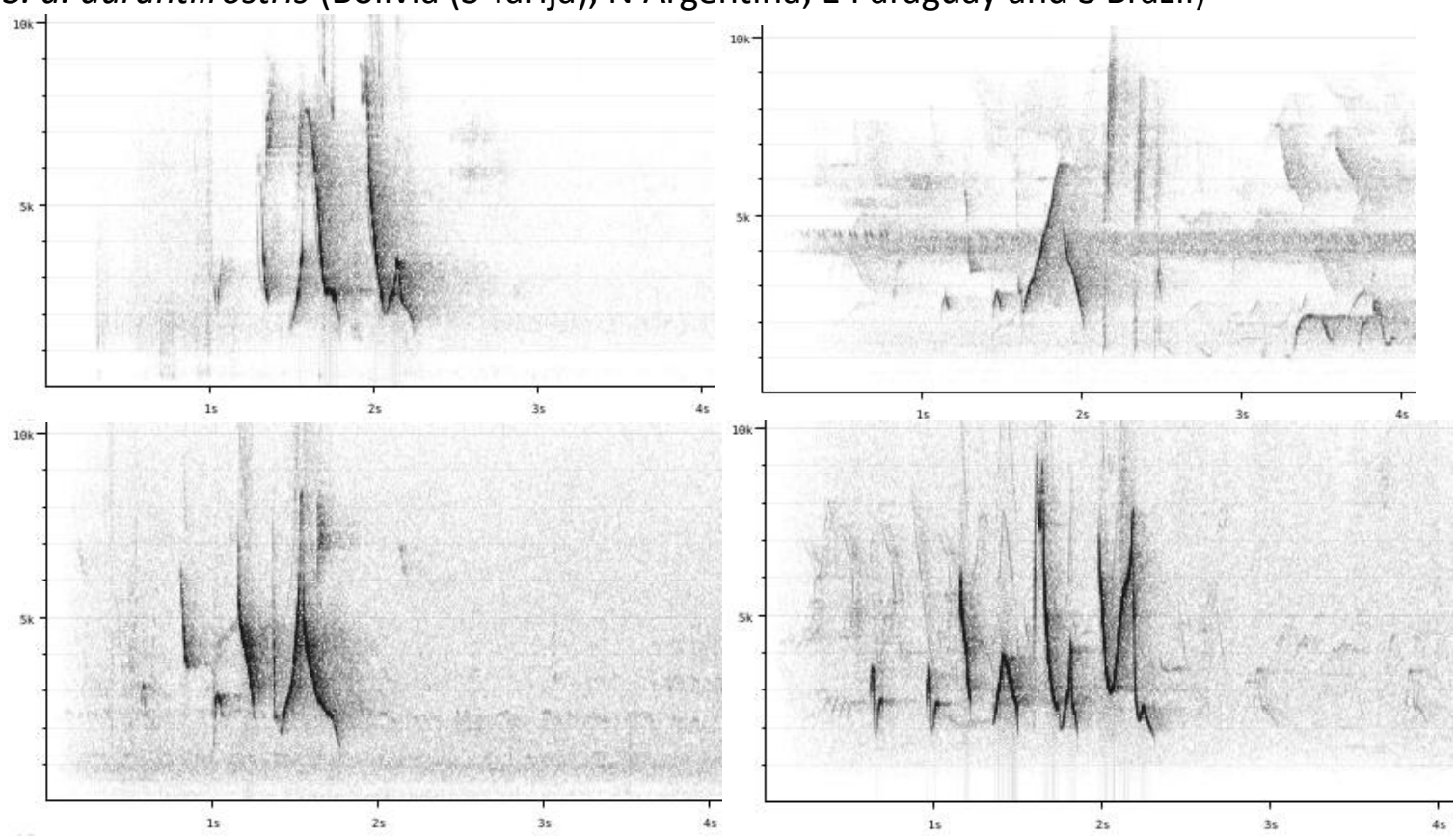

3 

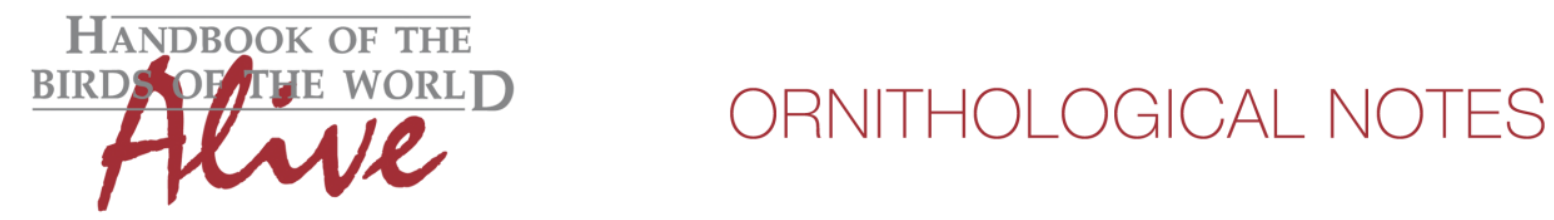

S. a. parkesi (E Argentina, extreme SE Brazil and Uruguay)
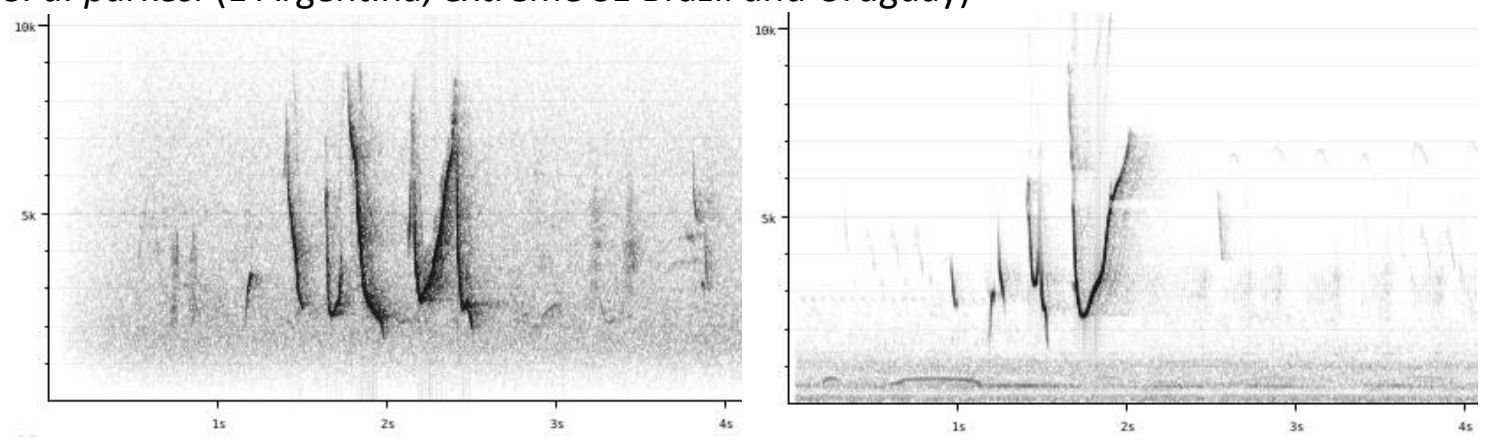

S. a. nasica ( CW Argentina): no recordings

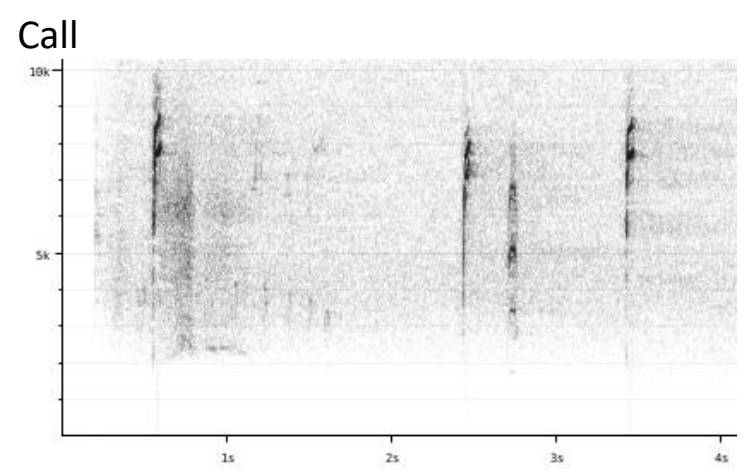

From the above, it is quite clear that song of all races in S. aurantiirostris is very similar, leading to a clear break with voice of $S$. nigriceps, which is very different.

Vocal differences can be quantified as follows:

Song of nigriceps is a single emphasized whistle preceded by a short intro note $v s$ a songphrase consisting of 3-8 notes (score 2-3), whistle is polyphonic ( $v s$ monophonic)( 2 notes at same time $v s$ always single note at same time, score 3 ), and whistle is longer than average duration of longest note in aurantiirostris (2).

Additional differences may be found in call notes, but at present only a few recordings are available.

We can thus conclude that the six subspecies of Golden-billed Saltator have a song with similar characteristics, very different from Black-cowled Saltator.

This note was finalized on 19th October 2016, using sound recordings available on-line at that moment. We would like to thank in particular the many sound recordists who placed their recordings for both species on XC.

\section{References}

Tobias, J.A., Seddon, N., Spottiswoode, C.N., Pilgrim, J.D., Fishpool, L.D.C. \& Collar, N.J. (2010). Quantitative criteria for species delimitation. Ibis 152(4): 724-746. 


\section{Recommended citation}

Boesman, P. (2016). Notes on the vocalizations of Black-cowled Saltator (Saltator nigriceps). HBW Alive Ornithological Note 440. In: Handbook of the Birds of the World Alive. Lynx Edicions, Barcelona. (retrieved from http://www.hbw.com/node/1287371 on 9 December 2016). 